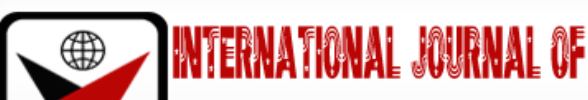

ISSN 2278-0211 (Online)

\section{Developing Teaching Slide Using the Rich Picture Approach of Soft System Methodology (Checkland)}

\author{
Trainer, House of Representative Training Center, Jakarta, Indonesia
}

Agus Supriyono

\begin{abstract}
:
In a learning or training process, teaching is an important tool in the transfer of knowledge to learners or training participants. This study seeks to build a teaaching slide design through the Rich Picture approach of Soft System Methodology (SSM). The main data used in this research is qualitative data, the data is collected through in-depth interviews with expert respondents and strengthened by the study of related documents or literature, the data were then analyzed qualitatively through interpretive techniques. As a result of this study, the author produced a design template of teaching slide by the Rich picture approach of SSM that can be changed or modified according to material needs, thinking and creativity. It is open and downloadable, with the result that anyone, especially educators, trainers or learning practitioners able to use or take advantage of it.
\end{abstract}

Keywords: Learning presentation material design, rich picture, soft system methodology

\section{Introduction}

In carrying out educational, teaching and training activities, a teacher or trainer is required to be able to prepare himself as well as possible. Preparations that need to be done before implementing the learning process are starting from how to compile a teaching material, designing teaching slide, structuring learning outlines, including determining the evaluation method that will be used. Winarry \& Faihaah (2016) explained that an educator or trainer is required not only to master the substance / learning material to be delivered, but also to be able to put the material to be taught into interesting teaching slide designs. The interesting teaching slide design will make the process of transferring experience and knowledge easier for the trainees to understand, and in turn will have a positive impact on the achievement of learning objectives.

The preparation of teaching slide often have not received special attention from educators / trainers. in general, teaching slide designs tend to only contain snippets of key words from the module. Besides being interesting and easy to understand, they must also be holistic, so that they can describe all the material to be delivered according to the demands of the learning module. teaching slides are generally still delivered partially and have not been delivered as a whole (holistically) which describes the mapping and the relationship between one material and another. To create an effective learning process, teachers or trainers are required to be able to produce teaching slide designs that do not only partially describe the sequence of each material or sub-material, but that can summarize the overall picture of the module content and the relationship between the materials (holistic) to make it easier for trainer and participants to achieve the desired learning objectives.

To make a teaching slide design more attractive, rich in meaning, and easier to understand, it should be built by incorporating infographic elements (text, images, graphics and videos). Infographics need to be adopted because they help the process of understanding content creatively, and have the advantage of explaining stories that cannot be told (Kominfo, 2018). Roam (2014) explains that through infographics which include; Appropriate text, images, sound and images will make it easier for participants to understand the material presented.

In Indonesia, research on the preparation of teaching slide design using the Rich Picture approach of SSM have not been widely carried out. So far, the Rich Picture has only been used as a strategy to solve various management problems that arise from the human activity system as part of social research (Checkland \& Scholes, 2007) (Hardjosoekarto, 2012) (Barusman M.B.A, 2017). Rich Picture is one of the stages in SSM which is a picture that is detailed and rich, which is displayed in the form of a picture or diagram. Rich picture informally captures the essence of the problem, structure and point of view of the situation, the ongoing process, actual recorded issues, and potential issues that will occur (Triyonggo 2016), or it is also called the representation of the current state (Fadhil et al. 2017). The use of image media in the form of a rich picture is considered better and easier to describe the complexity of human relations situations than linear prose or words (Checkland 2000). Rich pictures are known to be very versatile and therefore applicable and useful in a variety of contexts (see for example: Sutrisna \& Barrett, 2007; Bell \& Morse, 2010). The Rich Picture principles are closely related to 
the principles of teaching slide design as a medium in training, and therefore this study seeks to use the Rich Picture approach in building an effective and efficient teaching slide concept, which has never been studied before.

\section{Methodology}

The concept of teaching slide design to be built in this research is a case study for the training course of Building the Effective Team, at Level VI of Leadership Training. The main data used in this study are in the form of qualitative data. Data were collected through in-depth interviews with expert respondents and strengthened by document studies or related literature. Expert respondents came from infographic practitioners, writers of the Building the Effective Team module, SSM experts and enriched with 7 alumni of the PIM TK.IV Education and Training Class II Pusdiklat Setjen and BK DPR RI in 2019. To ensure that the selected respondents actually fit the required criteria, The determination of respondents was carried out using a combination of purposive sampling and snowball sampling with the following criteria: 1) Having adequate and relevant experience and / or education; 2) Have a good reputation and credibility in their respective fields; and 3) Willingness of time and communication to be interviewed.

In analyzing the data, the researcher did it qualitatively through interpretive techniques. In this technique, the researcher interprets the data through the formation of understanding and then compiles the results of the study based on their impressions in a structured results document. According to Ian Dey (1993), qualitative analysis has three processes, namely describing phenomena, clarifying them and analysing how emerging concepts are related to one another (Moleong, M.A, 2007). The stages of the research carried out were:

- Analyzing the modules that will be sampled in the study by identifying the module materials which are then grouped based on the elements in SSM;

- Building teaching slide design based on the element grouping that has been carried out using the SSM approach;

- Integrating teaching slide design with the SSM approach with the concept of infographics;

- Trial of teaching slide design using the SSM approach to alumni of the Level IV PIM training participants;

- Concepting Evaluation;

- Concepting improvements

\section{Results and Discussion}

The teaching slide design for The Building the Effective Team materials were built referring to the modules that have been officially validated and used so far. The Module of Building the Effective Team consists of 5 main topics, namely Effective Teams, Stakeholder Identification, Stakeholder Analysis, Influencing Stakeholders, and Communication Strategies. Referring to this module, the teaching slide of Building the Effective Team that has been used so far tends to be too much and wordy in explaining the material, even taking up more than 40 pages. The teaching slide design already uses infographic elements but is delivered partially and is not yet holistic, so there is no visible relationship between material and sub-material. After the application of the Rich Picture approach, the researcher produced a template that would allow other scholars to change the design of the teaching slide according to their thinking and creativity but still within the framework of SSM's Rich Picture. It provides a holistic development of content arrangement.

\subsection{Building the Design}

The design is built while referring to the content of Building the Effective Team-teaching slide design that has been used before, with some simplifications, and adding a design flow that shows the relationship between material and sub-material. The design is a summary description of the previous teaching slide infographic.

The design that has been built is then presented in a focus group discussion involving 2 experts (SSM experts and infographics experts), researchers and training managers, as well as obtaining considerations from module compilers and alumni of training participants. In general, the FGD participants felt interested in the design presented, and considered that through the design / concept of the material presented, the presentation process became simpler and easier to understand. SSM experts assess that SSM's Rich Picture principles have been accommodated in the design concept, while infographics experts highlight the fulfillment of infographic criteria with questions related to content, infographic design, arrangement of visual elements and movement of teaching slide. The inputs during the FGD then became a reference in building questions for the questionnaire filled out by respondents who were training alumni. The following are teaching slide designs that was built by considering various respondents' input.

\subsection{Teaching Slide Design of Chapter I: Introduction}

The content presented in this chapter describes an introduction to effective team building materials, including background, short descriptions, learning objectives, and names of subject matter. Based on respondents' input, there are changes to the design that has been built, by adding a sequence of explanations, and increasing the contrast of the background color. 


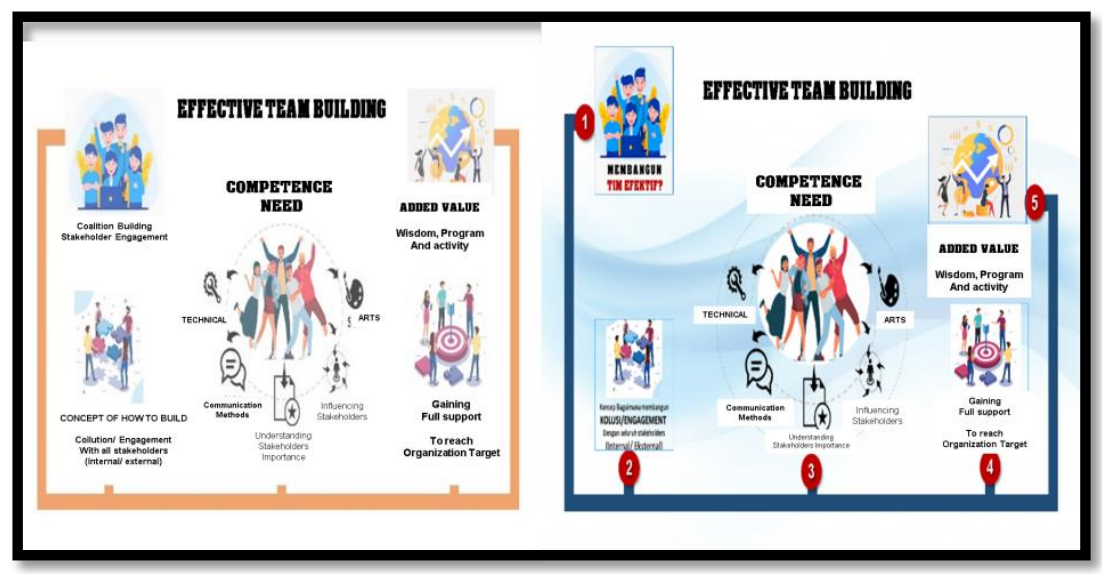

Figure 1: Teaching Slide Design of Chapter I

\subsection{Teaching Slide Design of Chapter II: The Effective Team}

The content for this chapter describes the concept of the effective team. The design of the presentation material that was built was considered by respondents to be appropriate so that there was no design improvement.

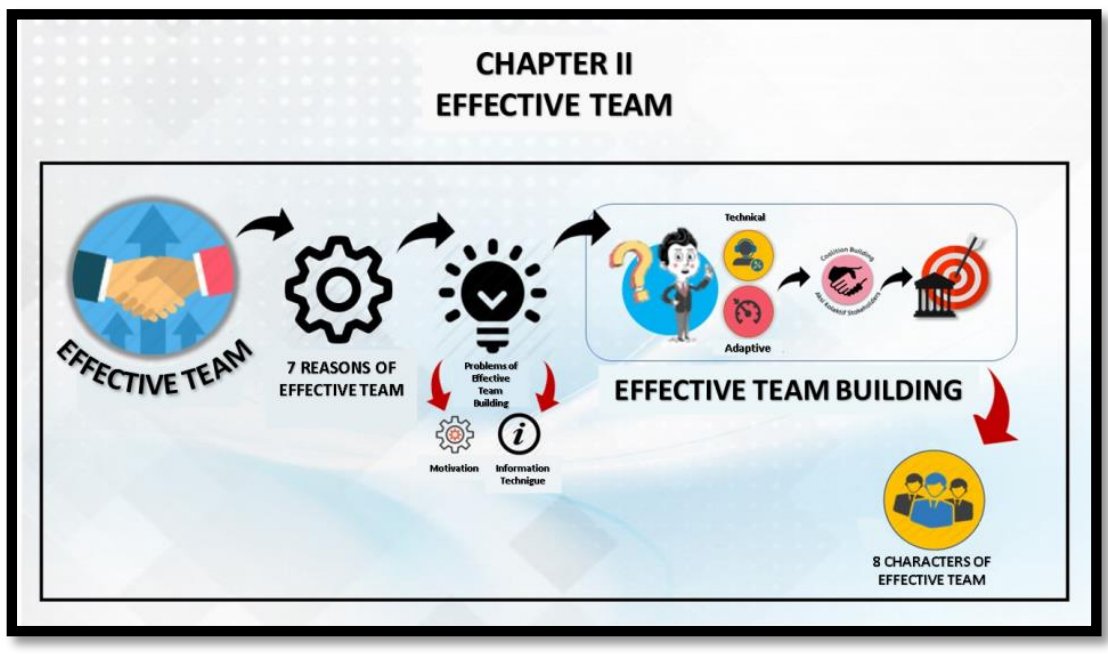

Figure 2: Learning Presentation Material Design of Chapter II

\subsection{Teaching Slide Design of Chapter III: Stakeholder Identification}

The teaching slide design for this chapter describes contents related to increasing participants' understanding of stakeholder definition, types of stakeholders and the relationship between stakeholders. The design was deemed appropriate so that there was no design improvement.

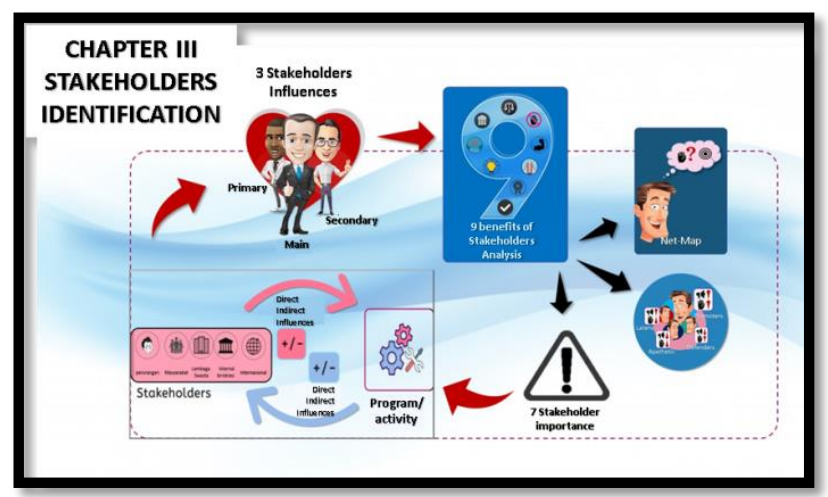

Figure 3: Teaching Slide Design of Chapter III

\subsection{Teaching Slide Design of Chapter IV: Influencing Stakeholders}

The content presented in this section describes material related to increasing participants' understanding of the concept of stakeholder analysis. The discussion begins with material related to mapping stakeholder goals, then mapping the influence and interests of stakeholders and ends with mapping stakeholder values. There is a change from the previously built design, by adding a sequence or number structure, and adding a circle connecting the four stakeholders to describe one unit in an activity. 


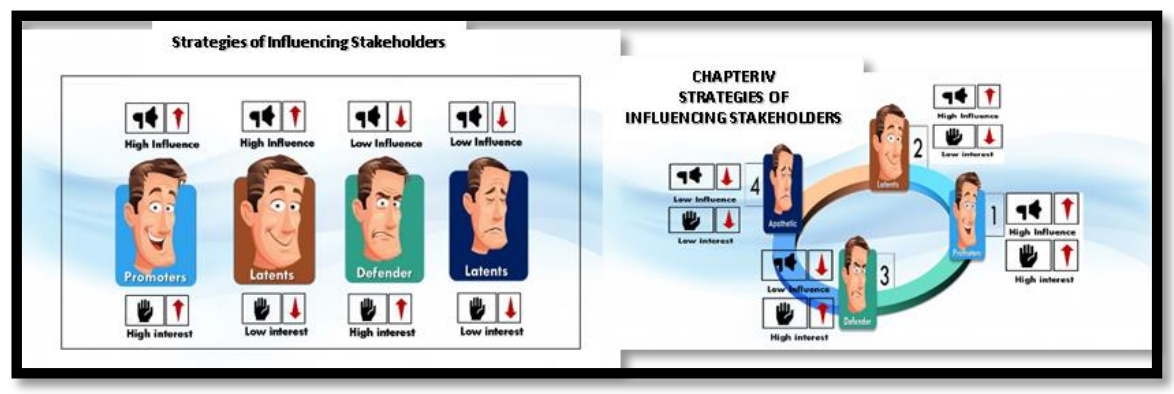

Figure 4: Teaching Slide Design of Chapter IV

\subsection{Teaching Slide Design of Chapter V: Communication Strategy}

The content for this chapter describes material related to communication patterns and strategies influencing stakeholders. There is a change from the previous design, by building a circular design that is considered more representative to show communication strategies.

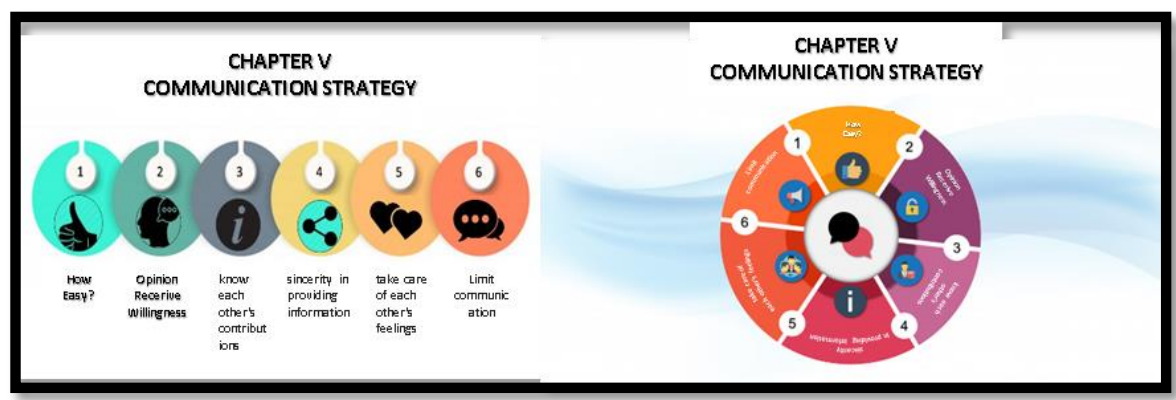

Figure 5: Learning Presentation Material Design of Chapter V

\subsection{Combined Teaching Slide Design of Chapter I - V}

Combined teaching slide design describes all material in the module, into one view. This combined teaching slide shows the sequences, flows and links between chapters. The design that was built was deemed appropriate so that there was no design improvement.

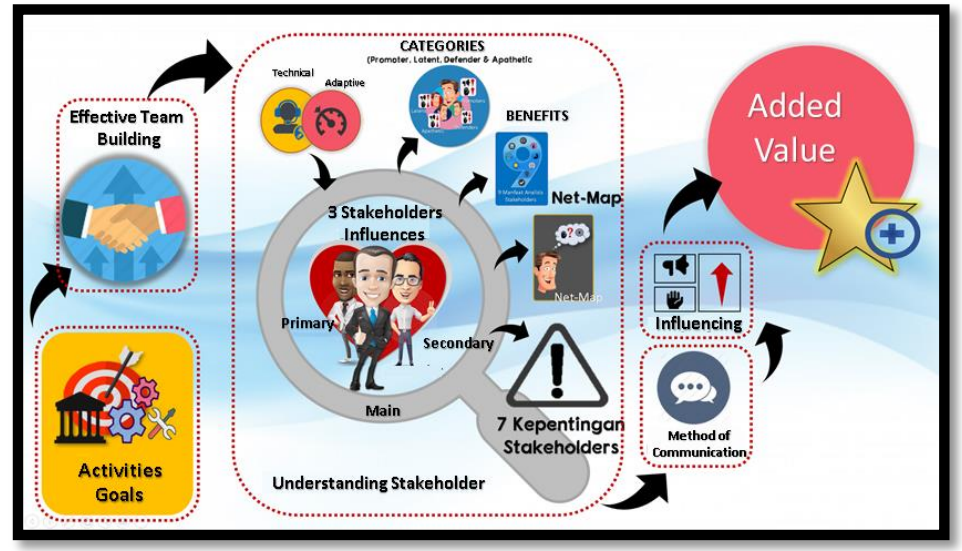

Figure 6. Combined Teaching Slide Design of Chapter I - V

\subsection{Research Output}

As a result of the research, the author produces a teaching slide template that allows anyone, especially trainers or learning practitioners to change the design according to their thinking and creativity but still within the SSM Rich Picture frame. Berg, Bell \& Morse (2019) explained that Rich Picture is a platform for imagination, sharing stories, concepts and facts, as well as imaginative thinking about all kinds of future potential. Therefore Rich Picture is not only about art appreciation, order or form but about meaning and expression through communication, understanding and human experience. These things are strived to be accommodated, in the design of the teaching slide that have been built in this study. Complete open content can be accessed via the following link:

https://drive.google.com/drive/folders/1SNHcG39C0VIKDHv0R7XU89Hi3_l_Djtx?usp=sharing

\section{Conclusions and Recommendations}

Designing the concept of teaching slide using the Rich Picture approach of SSM is a new option for a systems approach in the development of learning methods. Rich Picture is one of the SSM stages that offers a comprehensive and 
holistic overview of teaching slide in a learning process. The benefit of this method is that the viewing material is simpler which is able to summarize the overall material infographics more effectively and efficiently.

The use of the Rich Picture SSM in designing teaching slide needs to be tried and applied to other training materials apart from what has been practiced in this study. Rich Picture SSM provides new value and strengthens the infographic function, which has been the main reference in the preparation of teaching slide.

\section{References}

i. Barusman, D. Y. (2017). Soft System Methodology, Solusi untuk Kompleksitas Manajemen. Lampung`: Universitas Bandar Lampung.

ii. Bell, S., \& Morse, S. (2010). Rich pictures: a means to explore the 'sustainable mind'? Sustainable Development. 21 (1): 30-47.

iii. Berg, T., Bell, S., \& Morse, S. (2019). Using rich pictures outside of soft systems methodology: a case study analysis. Int. J. System of Enginering. 9 (3): 257-275.

iv. Checkland, P., \& Scholes, J. (2007). Sof System Menthodology in Action. Chichester: John Wiley \& Sons, LTD.

v. Checkland P. (2000). Soft systems methodology: a thirty-year retrospective. Syst. Res. Behav. Sci. 17:11-58.

vi. Fadhil, R. Maarif, MS., Bantacut, T. \& Hermawan A. (2017). Situational and Invention Strategy for Gayo Coffee Agoindustry Institution in Indonesia. Journal of Food Agriculture and Environment. 16 (1): 31-40. DOI: https://doi.org/10.1234/4.2018.5479

vii. Hardjosoekarto, S. (2012). Soft System Methodology. Jakarta: Penerbit Universtas Indonesia.

viii. Kominfo. (2018). Kiat Bikin Infografis Keren dan Berkualitas Baik. Jakarta: Kementerian Komunikasi dan Informatika Republik Indonesia.

ix. Moleong, M.A, P. J. (2007). Metode Penelitian Kualitatif. Bandung: PT. Remaja Rosdakarya.

x. Roam, D. (2002). Blah Blah Blah. Jakarta: PT. Elex Media Komputindo.

xi. Roam, D. (2008). The Magic of Picture. Jakarta: Ufuk Publishing House.

xii. Roam, D. (2014). Show and Tell. New York: Penguin Group.

xiii. Sutrisna, M. \& Barrett, PS. (2007). Applying rich picture diagrams to model case studies of construction projects. Engineering, Construction and Architectural Management. $14 \quad$ (2): 164-179. http://dx.doi.org/10.1108/09699980710731281

xiv. Triyonggo Y. (2016) Design of competence model of human resource management profession in Indonesia. Dissertation, Institut Pertanian Bogor, Bogor, Indonesia.

xv. Winarry, A., \& Faihaah, I. (2016). Kebijakan Pembinaan Widyaiswara dan Angka Kreditnya. Jakarta: Lembaga Administrasi Negara. 